\title{
SINERGIA
}

REVISTA DO INSTITUTO DE CIÊNCIAS ECONÔMICAS, ADMINISTRATIVAS E CONTÁBEIS (ICEAC)

\section{DISPONIBILIDADE E ACESSO AO CRÉDITO RURAL: A PERCEPÇÃO DOS PRODUTORES RURAIS DO MUNICÍPIO DE SÃO PEDRO DAS MISSÕES (RS)}

\author{
SIBELE VASCONCELOS DE OLIVEIRA \\ LIDIANE BINELLO DE OLIVEIRA* \\ RITA INÊS PAETZHOLD PAULI'
}

\begin{abstract}
O presente estudo tem por objetivo realizar a análise da percepção dos produtores rurais de São Pedro das Missões (RS) quanto à disponibilidade e ao acesso ao crédito rural e seus respectivos impactos sobre a inadimplência. Além da pesquisa bibliográfica e documental, procedeu-se à coleta e à análise de dados primários com produtores rurais. Os procedimentos de coleta de dados incluíram a adoção de uma amostragem não probabilística, compreendendo 100 entrevistas, realizadas entre março e abril de 2016. Dentre os resultados da pesquisa, cita-se a expressiva evolução dos recursos financeiros destinados ao crédito rural no Brasil. No que se refere à percepção dos produtores em relação aos recursos do crédito rural, três conclusões mais gerais merecem destaque: a) quase $2 / 3$ dos entrevistados consideram suficientes os incentivos direcionados ao crédito rural; b) o acesso ao crédito permitiu que a qualidade de vida da família aumentasse em $79 \%$; c) $62 \%$ dos entrevistados conhecem casos de inadimplência de produtores na circunvizinhança. Apesar dos avanços no volume de recursos financeiros, verificam-se, ainda, entraves que podem ser minimizados via gestão mais eficiente dos recursos pelos produtores e, ao mesmo tempo, revisão de aspectos dessa política, minimizando o viés concentrador dos recursos pelas organizações públicas.
\end{abstract}

Palavras-chave: Agronegócio. Crédito rural. Política agrícola. Plano Real

\section{ABSTRACT}

The present study aims to analyze the perception of the rural producers of São Pedro das Missões (RS) regarding the availability and access to rural credit and their respective impacts on the default. In addition to the bibliographical and documentary research, we collected and analyzed primary data with rural producers. Data collection procedures included the adoption of a non-probabilistic sampling, comprising 100 interviews, carried out between March and April 2016. The results of the research mention the significant evolution of financial resources destined to rural credit in Brazil. Regarding farmers' perceptions of rural credit resources, three more general conclusions are worth highlighting: a) almost $2 / 3$ of the respondents consider the incentives for rural credit to be sufficient; b) access to credit allowed the quality of life of the family to increase by $79 \%$; c) $62 \%$ of respondents are aware of delinquency in the surrounding area. Despite advances in the volume of financial resources, there are still obstacles that can be minimized through the more efficient management of resources by producers and, at the same time, the revision of aspects of this policy, minimizing the concentration bias of resources by public organizations.

Keywords: Agribusiness. Rural credit. Agricultural policy. Real Plan.

Recebido em: 24-01-2018 Aceito em: 25-05-2018

\section{INTRODUÇÃo}

Os agronegócios colocam o Brasil em destaque no mundo, sendo um dos líderes na produção e exportação de produtos agropecuários. O País ocupa a 9a posição no ranking das maiores economias do mundo. As atividades agropecuárias correspondem a expressivos $21,46 \%$ do Produto Interno Bruto (PIB) brasileiro. Dentre os fatores que contribuem para este desempenho, citam-se as condições climáticas favoráveis às atividades agropecuárias, o acesso à tecnologia que permite o aumento da produtividade e as características de gestão das propriedades rurais (MAPA, 2016).

A importância das atividades agropecuárias para o desenvolvimento da economia do País, através da

\footnotetext{
* Professora Adjunta do Departamento de Economia e Relações Internacionais e do Programa de Pós-Graduação em Economia e Desenvolvimento da Universidade Federal de Santa Maria. Doutora em Agronegócios (UFRGS), Mestre em Extensão Rural (UFSM) e Graduada em Ciências Econômicas (UFSM).

"Bacharel em Ciências Econômicas pela Universidade Federal de Sana Maria

" Doutora em Ciências Econômicas pela UNICAMP e Professora Associada do Departamento de Economia e Relações Internacionais da Universidade Federal de Santa Maria. Pesquisadora do Núcleo de Estudos Econômicos (NEEC/CNPq) da Universidade Federal de Santa Maria.
} 
geração de riquezas, emprego, divisas e recursos fiscais, faz com que os programas públicos e ações do governo federal neste setor cresçam. Diante desse fato, os produtores rurais são beneficiados direta e indiretamente, já que, por meio de investimentos, podem otimizar suas atividades, obter maior lucratividade e, por conseguinte, melhorar a qualidade de vida de suas famílias.

Vale ressaltar que é através do Plano Agrícola e Pecuário (PAP) ${ }^{1}$ que o governo federal disponibiliza crédito rural aos produtores, os recursos são direcionados ao custeio, investimento e comercialização das atividades agrícolas. As ações são realizadas de forma estratégica para que o País possa continuar aumentando a sua produção, abastecendo a demanda interna e garantindo participação na oferta de alimentos no mercado internacional (PAP, 2015/2016).

Sobretudo, a análise histórica das políticas públicas de apoio à produção e à comercialização agropecuária no Brasil permite observar que, após a implementação do Plano Real, em 1994, como uma ação de controle da inflação e valorização da moeda, a economia brasileira iniciou um processo de reorganização do Sistema Financeiro. Acompanhados a esse processo de estabilização econômica, houve uma crescente injeção de recursos pelo governo federal, direcionados ao crédito rural. Especificamente, uma das principais particularidades do crédito rural se refere às baixas taxas de juros anexadas aos financiamentos, inferiores às mantidas pelo mercado. $O$ baixo custo de acesso ao crédito rural, aliado à facilidade na aquisição e ao parcelamento do recurso financeiro, conquistou, ao longo do tempo, muitos adeptos que se comprometem com os financiamentos.

Se, por um lado, esse cenário de oportunidades faz avançar a procura pelo crédito rural, por outro, crescem os níveis de endividamento e inadimplência desses produtores. Neste sentido, evidencia-se que a ampliação da disponibilidade e acesso ao crédito permitiu a ampliação das possibilidades de endividamento dos produtores que usufruem do crédito rural, tornando consideravelmente mais altos os níveis de inadimplência neste meio. Este processo de endividamento dos produtores rurais é agravado, considerando-se que ainda é possível encontrar, principalmente nos produtores de pequeno porte, um nível de conhecimento intelectual muito baixo. Boa parte destes pequenos produtores se mantém nas áreas rurais com o trabalho repassado de pai para filho, com técnicas de cultivo basicamente empíricas e acesso à educação formal muito baixo.

Destarte, ressalta-se que a falta de informação, instrução ou conhecimento dos produtores rurais e o fácil acesso ao crédito, quando aliados, podem condicionar situações de insucesso no que se refere à gestão das atividades agrícolas e um rastro de dívidas dos produtores junto a instituições financeiras, tornando altos os níveis de inadimplência. Dessa forma, o presente estudo tem como problema de pesquisa: de que forma os produtores rurais percebem a crescente evolução do crédito rural, as suas facilidades de acesso e seus impactos sobre a inadimplência do meio rural? Sendo assim, o objetivo do presente estudo foi avaliar a percepção de produtores rurais da região de São Pedro das Missões (RS) acerca da evolução da disponibilidade do crédito rural, as suas facilidades de acesso e seus impactos no que se refere à inadimplência do meio rural.

Para tanto, realiza-se um estudo exploratório e de abordagem quali-quantitativa. Através das pesquisas bibliográficas e de campo, procede-se com a análise dos dados primários coletados junto a produtores rurais do município supracitado. Por conseguinte, à luz da literatura econômica sobre o desenvolvimento rural, debate-se sobre as oportunidades e desafios gerados pelo acesso ao crédito rural.

Por fim, vale mencionar que a redação deste artigo científico está organizada em seis seções, incluindo a presente introdução. Na seção 2, discute-se sobre as contribuições dos agronegócios brasileiros ao desenvolvimento rural, bem como das políticas agrícolas de fomento ao setor. Na seção 3, discorre-se sobre as condições de acesso dos produtores rurais ao crédito subsidiado pelos entes estatais e as situações de vulnerabilidade geradas, como o endividamento e a inadimplência dos agentes. Em sequência, são descritos os procedimentos metodológicos da pesquisa. A seção 5 é responsável por ilustrar os principais resultados do estudo. Já a seção 6 apresenta as considerações finais. Sem mais, listam-se as principais referências bibliográficas consultadas durante a execução do estudo.

\section{A IMPORTÂNCIA SOCIOECONÔMICA DO AGRONEGÓCIO NO BRASIL E AS POLÍTICAS AGRÍCOLAS DE INCENTIVO AO SETOR}

O agronegócio, no Brasil, realiza contribuição significativa para o desenvolvimento e crescimento do País, ao colocá-lo em uma posição de destaque, especialmente no que se refere à produção de alimentos e à exportação de produtos primários. Além do mais, de acordo com dados divulgados pelo Cadastro Geral de Empregados e Desempregados (Caged), a agropecuária gerou cerca de 9,8 milhões de empregos em 2015. O setor foi o único a apresentar saldo positivo, principalmente em função da ampliação da produção e das exportações.

\footnotetext{
${ }^{1}$ O PAP é divulgado anualmente por meio do Ministério da Agricultura, Pecuária e Abastecimento (MAPA) e consiste em uma série de medidas de política agrícola com o objetivo de promover facilidades e possibilidades para os produtores brasileiros (MAPA, 2016).
} 
Contribuem para o desempenho positivo das atividades agropecuárias, as condições climáticas favoráveis, tecnologia e gestão das propriedades rurais (MAPA, 2015). Outro fator expressivo que faz o Brasil apresentar vantagens competitivas em relação aos demais países produtores agrícolas do mundo refere-se à vasta extensão territorial brasileira para o cultivo. Segundo estimativas do Ministério da Agricultura, Pecuária e Abastecimento, o total de terras agricultáveis férteis e de alta produtividade no Brasil é de 388 milhões de hectares, dos quais 106 milhões ainda não foram explorados (MAPA, 2004). Fazem-se realçar ainda as vantagens brasileiras quanto ao acesso a fontes de água e à biodiversidade existente.

Com a ascensão do País no mercado mundial de alimentos e de produtos primários, crescem os investimentos governamentais em favor dos produtores rurais para a otimização de suas atividades produtivas. Assim sendo, através de políticas públicas, os produtores rurais também se sentem mais seguros para realizar investimentos que possibilitem aumento da renda e, consequentemente, maior qualidade de vida.

A articulação de políticas públicas, através da criação de programas que possam fortalecer as atividades rurais e promover a dinamização econômica, são iniciativas que buscam a melhoria constante e o desenvolvimento da produção local, trazendo eficiência no trabalho, qualidade dos produtos, geração de emprego e aumento da renda no meio rural. Com isso, tem-se por resultado o abastecimento do mercado doméstico e a maior competitividade dos produtos brasileiros no mercado internacional.

Segundo Schultz e Waquil (2011), a principal finalidade para intervenção governamental, através de políticas agrícolas, é para corrigir possíveis imperfeições e falhas no funcionamento dos mercados provenientes das particularidades que compõem o setor agrícola, como, por exemplo, a sazonalidade e a perecibilidade dos produtos. Essas falhas e imperfeições podem vir a afetar de forma negativa a sociedade, por isso a necessidade de o Estado intervir (SCHULTZ; WAQUIL, 2011).

Coelho (2001) argumenta que, especialmente desde a década de trinta, o estado brasileiro vem utilizando diferentes instrumentos de políticas agrícolas para incentivar o setor agrícola. Dentre as razões econômicas para a legitimação das ações governamentais, cita-se: a melhoria da alocação de recursos, redução das flutuações na renda e promoção da segurança alimentar (COELHO, 2001).

Conforme argumenta Coelho (2001), a história da Política Agrícola no Brasil pode ser dividida em quatro fases, a saber: a primeira, "fase da agricultura primitiva"; a segunda, "fase de modernização da agricultura"; a terceira, "fase de transição da agricultura" e a quarta, "fase da agricultura sustentável". Em detalhes, a fase da agricultura primitiva (1930 a 1965) foi marcada por diversas tentativas de sofisticar e ampliar a política. Este período foi também marcado pelas Políticas do Café, Política do Açúcar e do Álcool e Política Agrícola dos Grãos. Nesta fase, deu-se, em 1939, o início da Segunda Guerra Mundial; com o seu fim, em 1945, abriram-se novas perspectivas para os países que, como o Brasil, não tiveram suas economias destruídas. O momento seria ideal para o lançamento de políticas mais ousadas e mais abrangentes de desenvolvimento. Nesta fase, surgem as primeiras tentativas de formalizar uma política agrícola voltada para a produção de grãos no Brasil.

A fase de modernização da agricultura (1965-1985) contemplou a reforma do crédito rural; a reformulação da Política de Garantia de Preços Mínimos; o lançamento de Programas Especiais para Ocupação dos Cerrados, dentre outras ações. Os principais resultados positivos da nova política traduziram-se em estímulo à produção de grãos e à diversificação das exportações. Nesse período, manteve-se a Política do Café e do Açúcar, com maiores intervenções relacionados à geração de álcool, com o objetivo de reduzir a dependência do Brasil às importações de petróleo. Foi também criado o programa Proálcool (COELHO, 2001).

A fase da transição da agricultura (1985 a 1995) foi marcada pela aplicação de uma política restritiva, com a decisão de o Governo Federal eliminar o subsídio ao crédito, por meio do uso de indexadores e por reduzir de forma drástica a oferta do crédito rural. Este período sofreu influência dos vários planos que buscavam a estabilização dos altos índices de inflação e, também, a abertura comercial. Nesta fase, utilizou-se, frequentemente, a Política de Garantia de Preços Mínimos (PGPM) e observou-se forte endividamento do setor rural, antecedendo à reformulação geral dos instrumentos de política agrícola (COELHO, 2001).

Mais recentemente, a fase da agricultura sustentável (1995) traz a tentativa de o governo resolver o endividamento rural através da securitização, com o desenvolvimento e utilização de novos instrumentos de política agrícola. Também, nessa fase, intensifica-se a proposta de sustentabilidade, o tratamento cada vez mais recorrente de variáveis ambientais e do princípio da agricultura sustentável nas decisões de política agrícola e no cálculo econômico dos empresários rurais (COELHO, 2001).

Durante o interstício analisado, foram influentes sobre a dinâmica das políticas agrícolas os programas de estabilização da economia brasileira. Neste sentido, vale mencionar que, após inúmeros planos de estabilização malsucedidos, finalmente, em 1994, é lançado o Plano Real, que conseguiu controlar os altos índices de inflação. Contudo, em 2008, com a instalação da crise mundial, como forma de controle para conter a crise, o governo reduziu os financiamentos dos setores de produção que até então 
estavam quase totalmente nas mãos do setor privado, e direcionou, em partes, para a gestão do setor público. O setor público assume uma parte dos financiamentos de importantes setores, tais como o industrial e o agrícola (IPEA, 2011).

Conforme Demonstrações Financeiras do Banco do Brasil, no primeiro semestre de 2015, o Banco do Brasil operava no Sistema Nacional de Crédito Rural (SNCR) com expressivos $60,5 \%$ do total de financiamentos do setor agrícola, o que representa um incremento de 7,5\% em relação ao mesmo período de 2014. Assim sendo, o Banco do Brasil mantém maior parcela de participação nas operações direcionadas ao agronegócio, consolidando-se como o maior parceiro do agronegócio brasileiro (BANCO DO BRASIL, 2015).

Além do mais, percebem-se inúmeras iniciativas do governo federal através de políticas relacionadas à sustentabilidade, para o melhor aproveitamento dos recursos naturais, sem agressão ao meio ambiente. Nesse aspecto, destaca-se a importância da Empresa Brasileira de Pesquisa Agropecuária, (EMBRAPA), vinculada ao Ministério da Agricultura, Pecuária e Abastecimento (MAPA), que "atua fomentando a agricultura e pecuária nacional, através do desenvolvimento e transferência de novas tecnologias para os produtores nacionais" (EMBRAPA, 2015).

Tendo em vista a importância dos agronegócios para o desenvolvimento socioeconômico do Brasil, legitima-se a existência de aparato legal e institucional de apoio aos setores primários e agroindustriais. Nesse sentido, a próxima seção encarrega-se da apresentação das modalidades de crédito rural ofertadas aos produtores rurais brasileiros, das condições da oferta monetária, bem como de suas implicações sobre os processos de endividamento e inadimplência.

\section{CRÉDITO RURAL E A INADIMPLÊNCIA DE PRODUTORES NO BRASIL}

Segundo o Manual do Crédito Rural (MCR), podem acessar o crédito rural "produtores rurais, pessoa física ou jurídica, cooperativas de produtores rurais e pessoas físicas ou jurídicas que, mesmo não sendo produtores do meio rural, dediquem-se a alguma atividade ligada a este meio". É considerado crédito rural o suprimento dos recursos financeiros, por instituições do Sistema Nacional de Crédito Rural, para aplicação exclusiva nas atividades do setor do agronegócio (BANCO DO BRASIL, 2015).

$O$ crédito rural é dividido em três modalidades, e estas três subdivididas em diversas linhas de crédito. De acordo com o MCR, a modalidade de custeio é direcionada às diversas despesas dentro do ciclo produtivo, desde a compra de insumos até a fase de colheita. A modalidade de investimento refere-se à compra de bens ou serviços, cujos benefícios destes perdurem a longo prazo. Já a modalidade de comercialização destina-se ao armazenamento e à venda dos produtos agropecuários, ou para converter em espécie os títulos oriundos de sua venda ou para entregar os produtos em suas cooperativas (BACEN, 2015).

É atribuição do Sistema Nacional de Crédito Rural (SNCR) conduzir este segmento, "de acordo com as diretrizes da política creditícia formulada pelo Conselho Monetário Nacional, em consonância com a política de desenvolvimento agropecuário". Ao Banco Central do Brasil cabe o controle do SNCR e compete, entre outras obrigações, principalmente, dirigir, coordenar e fiscalizar o cumprimento das deliberações do Conselho Monetário Nacional, aplicáveis ao crédito rural (MCR, 2016).

Em relação às taxas de juros e parcelamento, específicas dos financiamentos pelo crédito rural, uma das principais questões que atrai inúmeros adeptos, entre pequenos e grandes, segundo o MCR, são as baixas taxas de juros, o parcelamento facilitado, as vantagens em relação ao tempo de carência dos pagamentos e, em alguns casos, a facilidade na renegociação do financiamento (BACEN, 2015).

Dentre tantas facilidades e atratividades, o produtor se mantém instigado a recorrer à obtenção do crédito desde a compra de insumos até a comercialização dos produtos. Ou seja, tem sua atividade financiada desde o início do processo, o desenvolvimento e as ferramentas necessárias para manter e aperfeiçoar sua produção, incluindo as fases de finalização do processo durante a venda do produto. Neste sentido, o propósito do crédito é o de habilitar e proporcionar ao produtor que alcance seus objetivos com o uso eficiente e consciente dos recursos disponíveis, nos quais se insere o crédito rural, para, com isso, movimentar e gerar riquezas para a economia do País.

A partir de então, é possível identificar as fragilidades que envolvem a obtenção do crédito, isto é, o nível de endividamento dos produtores que adquirem o crédito rural. O produtor rural vive esse problema, e, nesse contexto, surge a indagação: a crescente injeção pelo governo federal de valores direcionados ao crédito rural e a facilidade de acesso dos produtores a essas modalidades têm feito aumentar a preocupação em relação à crescente inadimplência neste meio? Em decorrência da procura intensiva dessas linhas de crédito, parte expressiva dos produtores acumula montantes de dívidas elevadas a serem pagas anualmente.

Os produtores rurais justificam a inadimplência, dentre vários motivos, pela vulnerabilidade das atividades agropecuárias às intempéries climáticas e às incertezas mercadológicas (ALFONSIN, 2015). A 
falta de um seguro agrícola mais abrangente também é um fator que influência no endividamento rural. No Rio Grande do Sul, a principal justificativa no que se refere à inadimplência é a de que os agricultores consideram o valor destinado ao seguro rural como sendo razoável. Outra dificuldade encontrada pelos produtores em não conseguir cumprir com as parcelas dos financiamentos diz respeito à elevação do preço dos insumos, o preço do produto muitas vezes não condiz com os custos despendidos para sua produção, fazendo com que o produtor não consiga faturar o suficiente para pagar tais custos (ALFONSIN, 2015).

Considerando os argumentos supracitados, as dificuldades climáticas e econômicas têm sido, na maioria das vezes, os principais agravantes que impossibilitam os produtores de efetuarem o pagamento do crédito rural. Porém, também tem sido observada a falta de planejamento financeiro a médio e longo prazo. A falta de um planejamento na propriedade, impossibilitando produtores de computar seus custos de produção e os riscos das atividades desenvolvidas, tem levado os produtores a recorrer à repactuação das dívidas (ALFONSIN, 2015).

Em outro aspecto, a falta de informação dos produtores e de conhecimento tem levado muitos a adquirir financiamentos de maquinário, induzidos por discursos de vendedores de grandes concessionárias de máquinas agrícolas, máquinas estas, em algumas situações, que não são próprias para a propriedade, sendo utilizadas de forma incorreta. Em algumas situações, os produtores também se comprometem com um financiamento, porém direcionam os valores financeiros para outras despesas diversas do objetivo inicial do crédito. Segundo a Sociedade Nacional da Agricultura (SNA), a inadimplência na carteira do crédito rural, no mês de julho, primeiro mês da safra de 2016/17, alcançou o patamar de $2 \%$, considerando operações com juros controlados para o produtor pessoa física, em âmbito nacional, segundo informações do Banco Central (SNA, 2016).

À luz das implicações diretas e indiretas das condições de oferta de crédito rural sobre o endividamento dos produtores agropecuários, propõe-se a realização de uma análise de dados secundários sobre o contexto brasileiro. Ademais, pretende-se promover uma pesquisa de campo, de forma a compreender com maior propriedade a realidade vivenciada por produtores do município de São Pedro das Missões (RS). Logo, a seção seguinte dá conta de especificar os procedimentos metodológicos adotados para tal fim.

\section{MATERIAL E MÉTODOS}

Com o objetivo de analisar a evolução da disponibilidade do crédito rural, a sua facilidade de acesso e os seus impactos sobre a inadimplência dos produtores rurais, optou-se por realizar uma pesquisa exploratória, descritiva, de abordagem quali-quantitativa, que se configura como um estudo de caso acerca da realidade do município de São Pedro das Missões (RS). Cabe destacar que, de acordo com Andrade (2010, p.112), "são finalidades de uma pesquisa exploratória, proporcionar maiores informações sobre determinado assunto e facilitar a delimitação de um tema de trabalho". Reitera-se, ademais, que procedimentos adicionais foram efetuados no presente artigo para proporcionar uma qualificação analítica mais completa, a partir do cuidado em relacionar os resultados com a evolução da política econômica no período em análise.

Em uma pesquisa de caráter descritivo, os fatos são observados, registrados e analisados, sem que os pesquisadores interfiram neles. Neste tipo de pesquisa, vale-se de técnica padronizada da coleta de dados, realizada principalmente através de questionários e da observação sistemática (ANDRADE, 2010, p. 112). Ademais, Michel (2009, p. 29) esclarece que uma pesquisa "qualiquanti" realiza o esforço de quantificar e percentualizar opiniões, submetendo seus resultados a uma análise crítica qualitativa.

Em síntese, a pesquisa foi dividida em duas etapas: a primeira parte teórica, de caráter exploratório, envolvendo a discussão das contribuições dos agronegócios para o desenvolvimento sobre a evolução e disponibilidade de crédito rural, nos períodos de 1994 a 2015. Neste sentido, o embasamento teórico é desenvolvido a partir de pesquisas bibliográficas e documentais ${ }^{2}$, respeitando o período estipulado.

Durante a segunda parte do estudo, instituiu-se uma pesquisa de campo, realizada no município de São Pedro das Missões, localizado na região Noroeste do estado, com aproximadamente 1.990 habitantes (IBGE, 2017). Para realizar o levantamento de dados primários quanto à percepção de produtores sobre a situação do acesso ao crédito e à inadimplência dos produtores, elaborou-se um instrumento de coleta de informações próprio, que foi aplicado no município de São Pedro das Missões (RS), nas linhas Pizze, Brizolla, Binello, Zandoná, Esquina Bonita, Espinilho, Paz e Barro Preto.

Ainda, a amostra pode ser definida como do tipo não-probabilística. Segundo Stevenson (1986),

\footnotetext{
${ }^{2}$ Segundo Gil (2017, p. 28-29), "a pesquisa bibliográfica é elaborada com base em material já publicado. Tradicionalmente, esta modalidade de pesquisa inclui material impresso, como livros, revistas, jornais, teses, dissertações e anais de eventos científicos". Por outro lado, "a pesquisa documental vale-se de toda sorte de documentos, elaborados com finalidades diversas, tais como comunicação, relatos de pesquisas, relatórios e boletins, compilações estatísticas etc".
} 
amostragem não-probabilística depende de critério e da avaliação estabelecida pelo pesquisador para se alcançar uma amostra fiel. As vantagens de se trabalhar com este tipo de amostra é a de que a análise se faz com maior agilidade. Sendo assim, a amostra utilizada foi selecionada por conveniência. Segundo Anderson, Sweeney e Williams (2007), amostras por conveniência permitem ao pesquisador a escolha do tamanho da amostra a ser trabalhada e a definição das estratégias de aproximação ao entrevistado.

A amostra realizada pela pesquisa atingiu 100 propriedades rurais. Considerando que o município de São Pedro das Missões possui 646 estabelecimentos agropecuários, $15,48 \%$ do total de gestores dos estabelecimentos agropecuários do município foram entrevistados. A pesquisa de campo foi realizada de 25 de março a 20 de abril de 2016. Os pesquisadores dirigiram-se aos produtores rurais, em suas casas ou estabelecimentos rurais, realizando a interrogação direta sobre os temas relacionados ao acesso ao crédito, ao crescimento da inadimplência e ao endividamento de seus pares do meio rural.

O instrumento ${ }^{3}$ de coleta de dados foi elaborado de tal forma que está dividido em blocos, desenvolvido com estas questões: culturas plantadas; comprometimento da renda com financiamentos; quais tipos de financiamentos o produtor acessa, entre outras questões que possam levar a uma análise e à conclusão referente ao problema de pesquisa proposta. Um dos objetivos deste questionário também é saber dos produtores rurais como eles avaliam as questões de política de crédito do País, qual a importância deste acesso e como eles têm aplicado e administrado este recurso nas suas propriedades.

A próxima seção apresenta os principais resultados da pesquisa de campo e da coleta de dados secundários sobre a temática do estudo.

\section{RESULTADOS E DISCUSSÕES}

Esta seção apresenta a análise dos dados secundários e primários, tal explicitação confronta e qualifica o referencial bibliográfico. Em especial, avaliam-se os resultados da pesquisa documental referente à disponibilidade de crédito rural no Brasil, no período de recorte indicado, de 1994 a 2015, bem como a realização da interpretação e discussão dos resultados obtidos a partir da aplicação dos questionários no município de São Pedro das Missões - RS.

\subsection{Análise da disponibilidade de crédito rural no Brasil}

Devido à importância do setor rural para a economia do País, é possível observar uma constante evolução dos recursos direcionados a este setor pelo governo federal no decorrer dos anos, em uma tentativa de manter e desenvolver ainda mais esta atividade. Entretanto, este setor possui especificidades; quanto ao ciclo de produção, está sujeito a intempéries climáticas, oscilações nos preços de insumos, volatilidade cambial, entre outras características particulares. Tais particularidades refletem na disponibilidade de recursos do crédito rural e, consequentemente, no acesso por parte dos produtores a estes recursos (AGUIAR; FREITAS, 2009).

Anualmente, o Governo Federal, por meio do Plano Agrícola e Pecuário (PAP), divulga os valores direcionados ao agronegócio que serão distribuídos dentro das modalidades de crédito, aos bancos públicos, privados e cooperativas, para, então, chegar às mãos dos produtores rurais e suas respectivas propriedades, em forma de investimento, produção e geração de renda (MAPA, PAP 2015/2016). A Figura 1 demonstra a evolução dos recursos financeiros auferidos ao crédito rural e acessados pelos produtores, abrangendo as atividades voltadas ao agronegócio, agrícola e pecuária, entre os anos de 1994, ano da implementação do Plano Real, até 2015.

\footnotetext{
${ }^{3} \mathrm{O}$ instrumento de coleta de dados foi construído após pesquisa bibliográfica e documental sobre o objeto de estudo. Sendo assim, as questões formuladas embasaram-se na literatura especializada. As pré-aplicações do instrumento de pesquisa ocorreram nos primeiros meses do ano de 2016 e tiveram por objetivo: testar o questionário, detectar incoerências ou potenciais erros, além de permitir ajustes de forma a aproximar os pesquisadores do público alvo do estudo.
} 


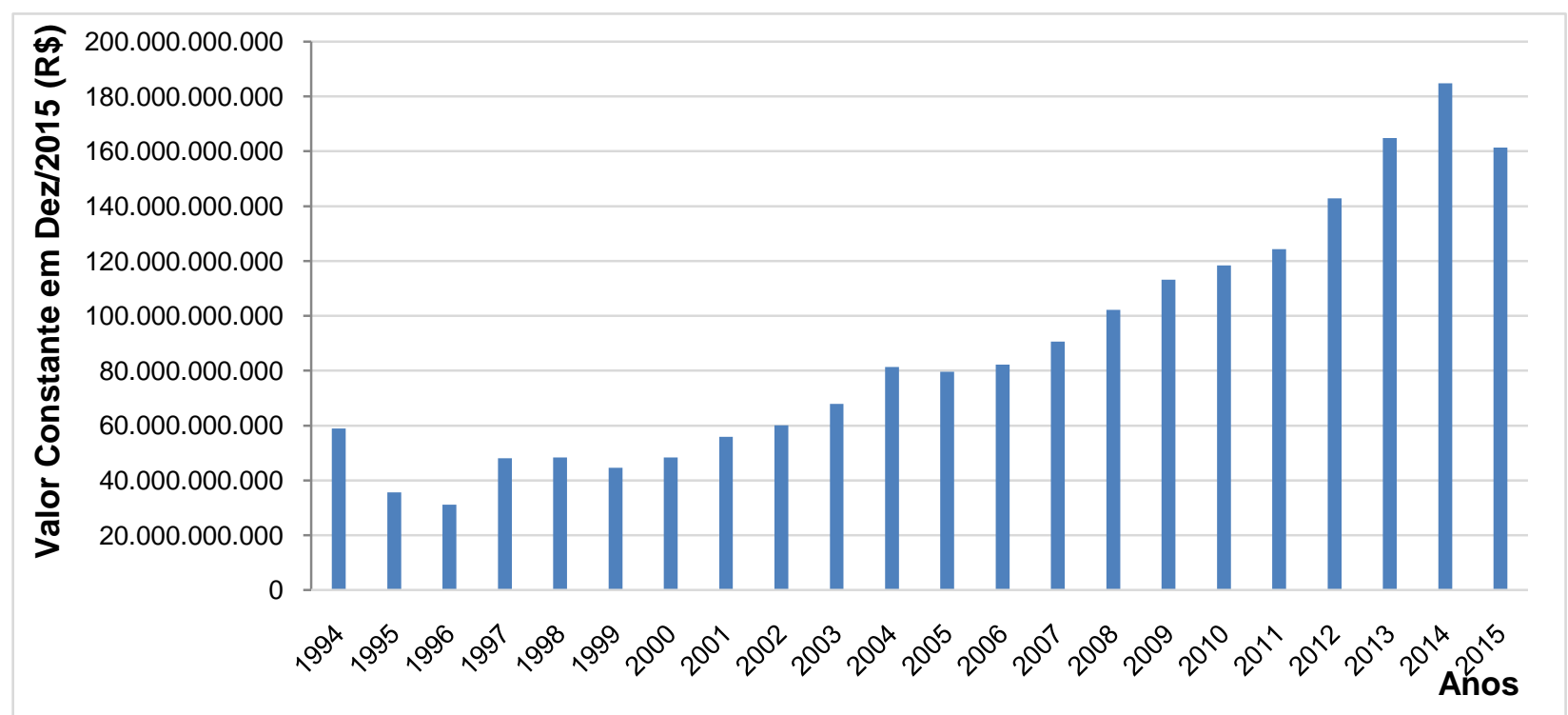

FIGURA 1 - Evolução dos recursos financeiros auferidos ao crédito rural no Brasil (1994 - 2015)

FONTE: Adaptado de Banco Central do Brasil (2016).

A partir da análise da figura 1, é possível identificar que, mesmo em meio a oscilações em determinados períodos na disponibilidade de recursos ao crédito rural, verifica-se, ainda assim, uma tendência a cada safra de aumento significativo dos valores revertidos ao crédito rural. De acordo com os dados disponibilizados pelo Banco Central (2016), é possível identificar que, desde o ano de 1999, houve uma crescente injeção de recursos direcionados ao crédito rural, que se deu em função da implementação do Plano Real. O Plano Real foi fundamental para o controle inflacionário e, com isso, o setor rural deixou de atuar num cenário instável e de inflação alta (TOSCHI, 2006).

Toschi (2006) destaca que, dentre algumas medidas adotadas pelo Plano Real, considera-se de grande impacto a maior abertura ao comércio exterior, as mudanças de política industrial visando à inserção mais competitiva de produtos nos mercados internacionais e as reformas no ordenamento constitucional do País. Com o novo cenário de estabilização, o governo iniciou a reforma da política agrícola no País, instituindo uma taxa fixa de juros ao ano (TOSCHI, 2006).

Com a introdução de reformas constitucionais de ordem econômica e pública, houve, também, o reordenamento do cenário em que operavam os bancos. Assim, o setor rural passou a contar somente com a exigibilidade bancária sobre os depósitos à vista, o que agravou a situação de inadimplência no meio rural $\mathrm{e}$, consequentemente, atingiu o sistema financeiro em seu todo. $\mathrm{O}$ crédito rural provocou algumas distorções, ao mesmo tempo em que teve um importante papel na modernização da agricultura e, também alavancou endividamentos para o produtor, acarretando prejuízos aos cofres púbicos (FIALHO; REDIN, 2009).

Segundo Braun e Shikida (2004), a valorização da moeda brasileira em relação ao dólar causou a queda de preços na economia brasileira, principalmente dos produtos do setor rural. Ao final de 1995, o governo federal iniciou a renegociação das dívidas rurais, de fundamental importância para a recuperação do setor.

No ano de 1999, ano em que o governo adotou o sistema de taxa de câmbio flutuante, o setor rural reagiu de forma positiva e, a partir daí os valores destinados ao crédito rural, se mantiveram em ascensão (TOSCHI, 2006). Em 2005, pôde-se observar uma retração nos valores destinados ao crédito rural. De acordo com Aguiar e Freitas (2009), neste ano, o setor do agronegócio sofreu com intempéries climáticas e queda de preços das commodities, associadas a uma superprodução de soja, o que reduziu, drasticamente, os preços no mercado internacional.

Em 2008, as exportações do agronegócio chegaram ao recorde histórico de US $\$ 71,8$ bilhões, com o boom dos preços das commodities agrícolas, porém, com a crise internacional, foram tomadas medidas provisórias para aumentar os investimentos de forma que a crise não afetasse o bom desempenho auferido pelo setor (AGUIAR; FREITAS, 2009).

Nos anos de 2013 e 2014, o sistema chega ao ápice de recursos demandados ao financiamento das atividades do setor agropecuário. Nesses anos, deu-se a recuperação da economia mundial, que refletiu de forma positiva nas economias emergentes. A retomada das atividades em 2013 foi basicamente sustentada pelo crescimento da agropecuária, "as cotações internacionais das commodities agrícolas e metálicas preservaram trajetória decrescente ao longo de 2013, em ambiente de melhores condições de oferta e crescimento chinês aquém do previsto" (BACEN, 2013, p. 11). 
O segmento de crédito rural possui especificidades que o fazem um sistema tratado de forma especial no mercado de crédito bancário. As taxas de juros vinculadas ao crédito são fixadas pelo governo federal e, assim como as condições de pagamento, são diferenciadas, inferiores às taxas e condições praticadas no mercado livre. Sustentar as taxas e condições inferiores às do mercado financeiro se caracteriza como uma política econômica adotada pelos governos como forma de fortalecer o setor (AGUIAR; FREITAS, 2009).

Por meio de pesquisa documental, é possível identificar uma crescente evolução no que se refere à disponibilidade e ao acesso ao crédito rural. No período de 1994 a 2015, como consequência dessa maior disponibilidade, evolui, também, o acesso dos produtores rurais, que, principalmente instigados pelas baixas taxas de juros, procuraram os bancos para ter acesso ao crédito. A situação de ampliação da disponibilidade e acesso ao crédito apresenta forte relação com o nível de endividamento dos produtores rurais, o que pode representar, em alto nível, grandes prejuízos ao Sistema Financeiro Nacional e, consequentemente, à economia do País de uma forma geral, como já aconteceu em outros momentos da história do SFN.

\subsection{Análise da percepção dos produtores rurais em relação às políticas de crédito}

A coleta de dados primários desta pesquisa foi realizada com 100 produtores rurais do município de São Pedro das Missões (RS). As perguntas foram desenvolvidas com o intuito de saber dos produtores qual a percepção dos mesmos em relação à disponibilidade e o acesso destes aos recursos destinados ao crédito rural. $O$ instrumento de coleta de dados era composto por perguntas que contemplavam a caracterização do perfil dos entrevistados, as características da propriedade e das atividades realizadas, bem como sua opinião acerca das políticas de crédito direcionadas ao meio rural.

A amostra foi composta por $86 \%$ de respondentes do sexo masculino. A média de idade situou-se em 51 anos; $50 \%$ dos entrevistados possui o Ensino Fundamental incompleto, enquanto $10 \%$ chegaram ao grau de Ensino Superior Completo. A média da renda mensal manteve-se na faixa entre 3,1 a 5 salários mínimos, correspondendo a $38 \%$ dos entrevistados. Ainda, $88 \%$ dos participantes da pesquisa são casados e a média de pessoas residentes na casa é de 3 pessoas.

As questões relacionadas às características da propriedade, à atividade desempenhada e ao acesso ao crédito rural foram subdivididas em questões abertas e fechadas. A saber, $23 \%$ dos produtores rurais entrevistados cultivam menos de 10 hectares. Os produtores que plantam entre 10 e 40 hectares representam $42 \%$ da amostra. Os produtores, com área disponível superior a 40 hectares e menor que 90 hectares, representam $19 \%$ da amostra e, dentro deste percentual, todos mantêm sua principal renda advinda da cultura da soja. Os demais participantes que correspondem a $16 \%$ dos entrevistados têm suas áreas plantadas entre 120 a 1600 hectares e tem, na cultura de soja, a principal renda da propriedade.

Ainda referente à questão sobre as culturas desenvolvidas pelos produtores rurais, como uma característica do município de São Pedro das Missões, o cultivo de sementes está concentrado na cultura da soja, com uma área plantada de 4.800 hectares e uma produção de 14.400 toneladas da oleaginosa (IBGE, 2014). Com os produtores entrevistados, a soja foi a cultura que se destacou como sendo a principal renda da propriedade, abrangendo $70 \%$ do total de entrevistados.

Somente $7 \%$ dos produtores entrevistados têm seus produtos vendidos em feiras locais e de cidades vizinhas, no comércio local, nas escolas do município ou em municípios que fazem divisa. Alguns mantêm produção somente para consumo próprio e da família.

Em algumas questões, as respostas foram distribuídas em escalas de Likert e dispostas entre cinco opções de respostas (opções: 1 - Totalmente suficiente, 2 - Insuficiente, 3 - Nem suficiente/Nem insuficiente, 4 - Suficiente a opção 5 - Totalmente suficiente). Cita-se a avaliação realizada pelos produtores rurais quanto aos incentivos que o governo federal tem revertido em prol da agropecuária. Em síntese, $18 \%$ dos produtores revelaram que os recursos são "Insuficientes", enquanto $47 \%$ revelaram ser "Suficiente" os recursos destinados ao crédito rural, tendo como objetivo o maior desenvolvimento da agropecuária. A figura 2 permite a melhor visualização destes resultados. 


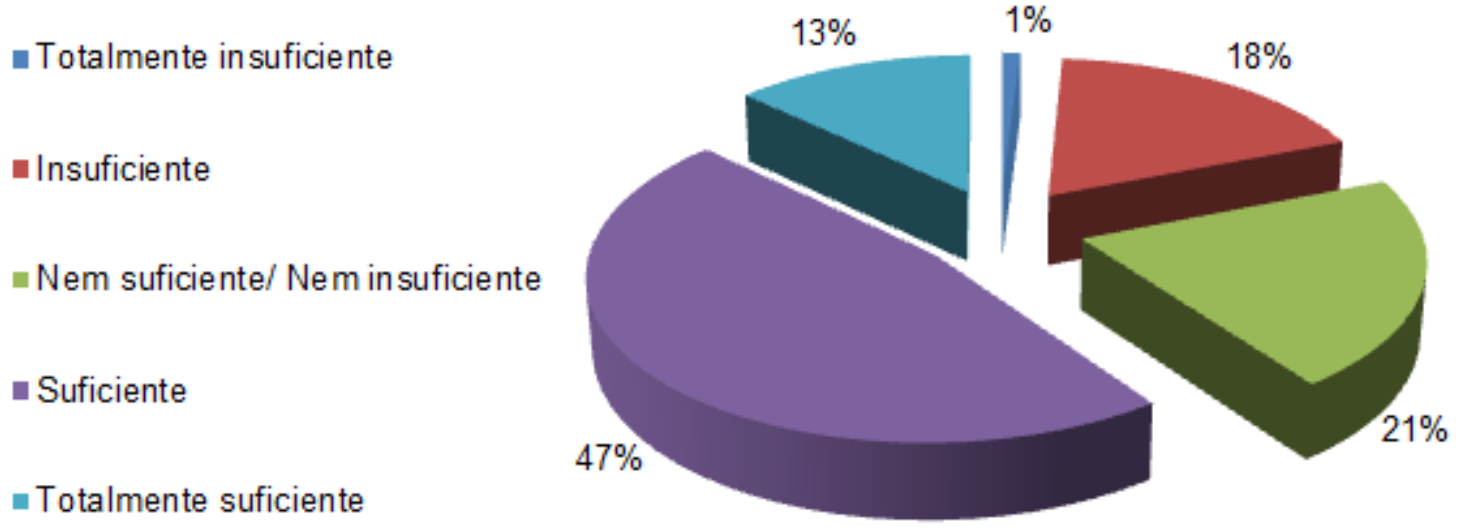

FIGURA 2 - Avaliação dos produtores rurais de São Pedro das Missões (RS) acerca dos incentivos governamentais voltados à agropecuária

FONTE: Dados da pesquisa de campo (2016).

Tendo em vista o percentual relevante de $60 \%$ dos entrevistados que acreditam ser "Suficiente" e "Totalmente Suficiente" os recursos direcionados pelo Governo Federal ao setor agropecuário, surge a questão de como vêm sendo distribuídos estes recursos, uma vez que, de acordo com as entrevistas, sendo suficientes os recursos, ainda não se concretizam como volumes que atendam às necessidades que norteiam o contexto do meio rural em suas especificidades. Nesse sentido, todos os produtores rurais entrevistados no município de São Pedro das Missões acessam o sistema de crédito rural. Destes, $42 \%$ acessam o segmento de custeio, e $20 \%$ acessam o segmento de investimento. Ainda um percentual expressivo, $38 \%$ dos produtores entrevistados acessam tanto o segmento de custeio como o de investimento, conforme explicitado na figura 3.

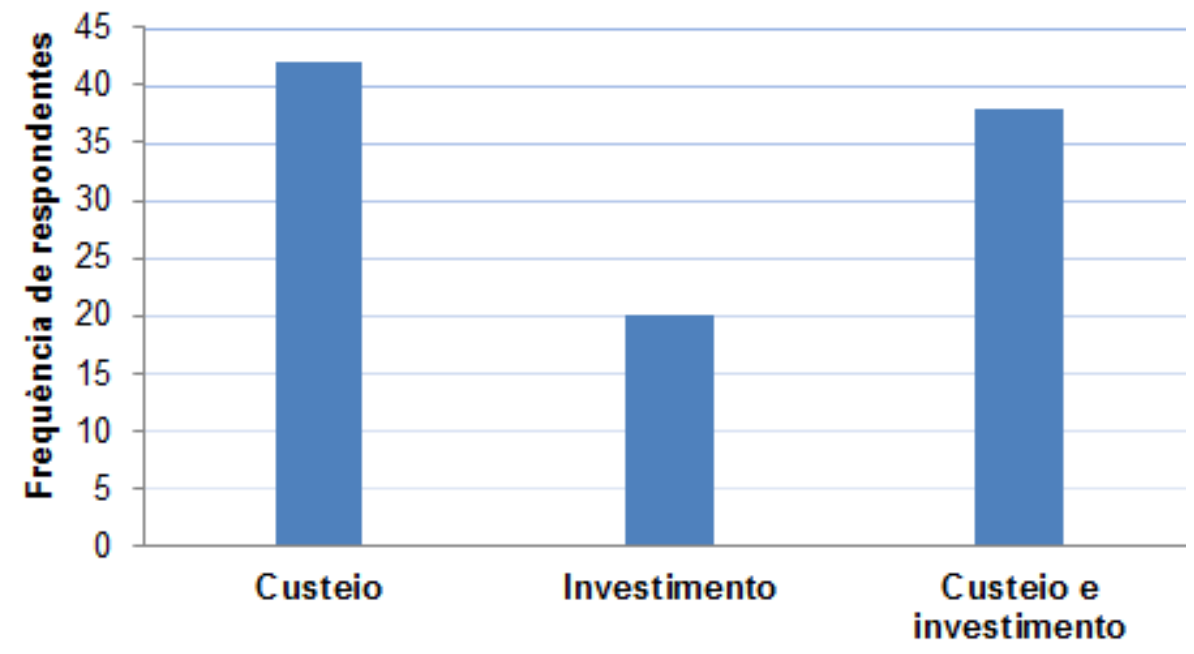

Modalidade de crédito rural

FIGURA 3 - Modalidades de crédito acessadas pelos produtores de São Pedro das Missões (RS) FONTE: Dados da pesquisa de campo (2016).

Vale notar que o segmento de comercialização não foi acessado por nenhum entrevistado e muitos argumentam não conhecer esta modalidade de crédito. De fato, o segmento de comercialização é mais utilizado por grandes produtores rurais, empresas privadas ou cooperativas de produção agropecuária, que se utilizam deste recurso para permitir o armazenamento e a conservação dos produtos agropecuários, visando à comercialização em melhores condições de mercado, com melhores preços. Como a amostra contemplada na pesquisa entrevistou, na sua grande maioria, produtores de pequeno e médio porte, justifica-se a não informação e o conhecimento pelos produtores quanto a essa linha de financiamento.

Referente às quantias monetárias acessadas pelos produtores rurais entrevistados, considerando o último acesso realizado pelos mesmos, os resultados demonstram a média referente ao segmento de custeio de $\mathrm{R} \$ 53.755,00$. Por outro lado, no segmento de investimento, a média acessada pelos produtores foi de $R \$ 82.377,00$.

Dentre os entrevistados na pesquisa, $47 \%$ procura o Banco do Brasil para intermediar as ações no 
que se refere aos financiamentos de custeio e investimentos realizados. Ainda, 33\% procuram os serviços da cooperativa Sicredi e os demais ( $20 \%$ da amostra) utilizam dos serviços dos bancos públicos Banrisul, Caixa Econômica Federal e, também, Cooperativas: Crehnor e Cresol.

Quanto aos prazos de pagamento das dívidas, $87 \%$ dos produtores avaliam como sendo prazos entre "Bom" e "Ótimo". Ademias, avaliam, de forma positiva, o tempo de carência vinculado ao crédito. Ademais, algumas questões abertas foram lançadas com o objetivo de que os produtores pudessem expor suas opiniões em relação às políticas de crédito e suas aplicações. Para fazer a análise destes dados, por se tratar de questões abertas, de opinião própria, foram separadas as respostas e, após, agrupadas de acordo com suas semelhanças.

Quanto às questões referentes à avaliação das taxas de juros aplicadas às linhas de financiamento, a avaliação dos produtores se manteve como: $35 \%$ avaliam as taxas entre "Muito altas" e "Altas"; $31 \%$ como "Regular"; $34 \%$ avaliam as taxas como sendo entre "Baixas" e "Muito baixas".

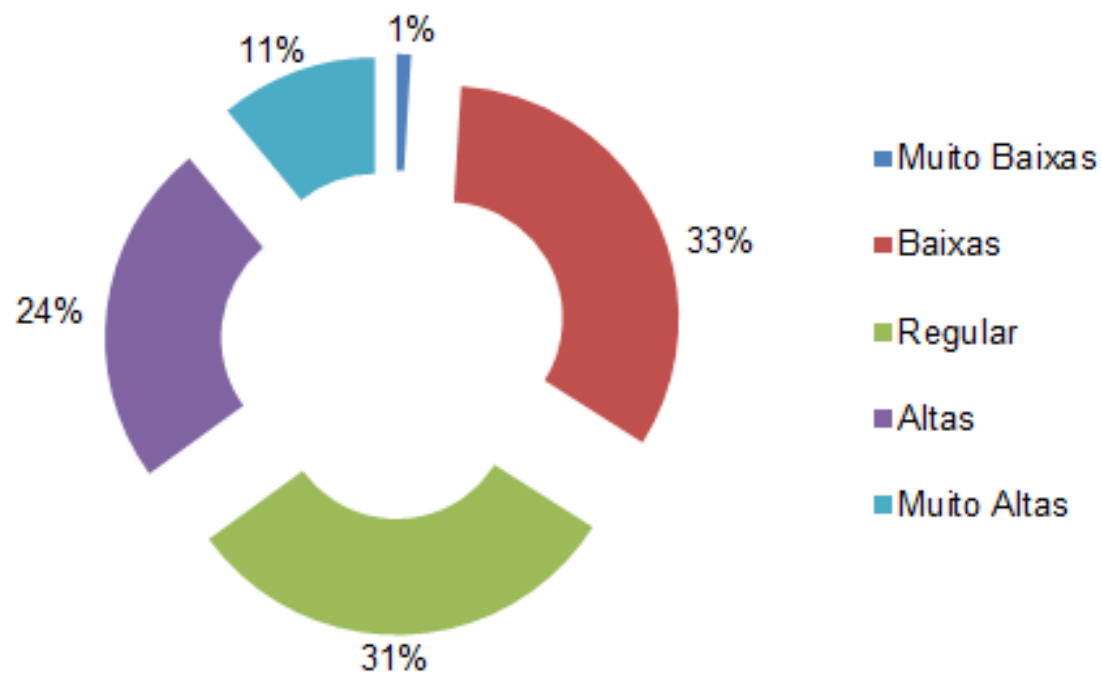

FIGURA 4 - Avaliação dos produtores rurais de São Pedro das Missões acerca das taxas de juros praticadas ao crédito rural FONTE: Dados da pesquisa de campo (2016).

De acordo com as respostas do grupo de produtores entrevistados, os principais entraves e dificuldades enfrentadas pelos mesmos para ter acesso aos recursos do crédito rural se resumem à inadimplência dos produtores junto às instituições financeiras. A burocracia e a capacidade de pagamento dos produtores também foram citadas pelos produtores como entraves de acesso ao crédito rural.

Em relação ao acesso aos recursos do crédito rural e como este se reflete na qualidade de vida das famílias residentes e que trabalham nas atividades do meio rural, todos os entrevistados concordam que, uma vez que a produção é bem realizada e o produtor pode contar com crédito a juros acessíveis, há o aumento de renda da família, por conseguinte, há expansão da qualidade de vida dos indivíduos.

Ainda, como consequência do acesso ao crédito, expressivos $80 \%$ dos entrevistados afirmam que houve aumento da produção, após terem acesso aos recursos financeiros investidos na atividade. $81 \%$ dos entrevistados afirmaram ter tido aumento da renda após ter acessado o crédito.

Referente ao percentual da renda dos produtores comprometido com financiamentos do crédito rural, a média desta variável dentro da amostra situou-se em 38,4\%. Na figura 5, é possível observar o comprometimento da renda dos produtores entrevistados com o crédito rural.

É possível observar que o percentual daqueles produtores que não possuem nenhum débito junto ao sistema referente ao crédito rural também se faz significativo, representando $16 \%$. Ainda, $60 \%$ dos produtores mantêm comprometido menos da metade do total da renda ou não há nenhum comprometimento. Portanto, a evolução na disponibilidade e acesso ao crédito rural não possui relação, neste caso, com o nível de inadimplência. 


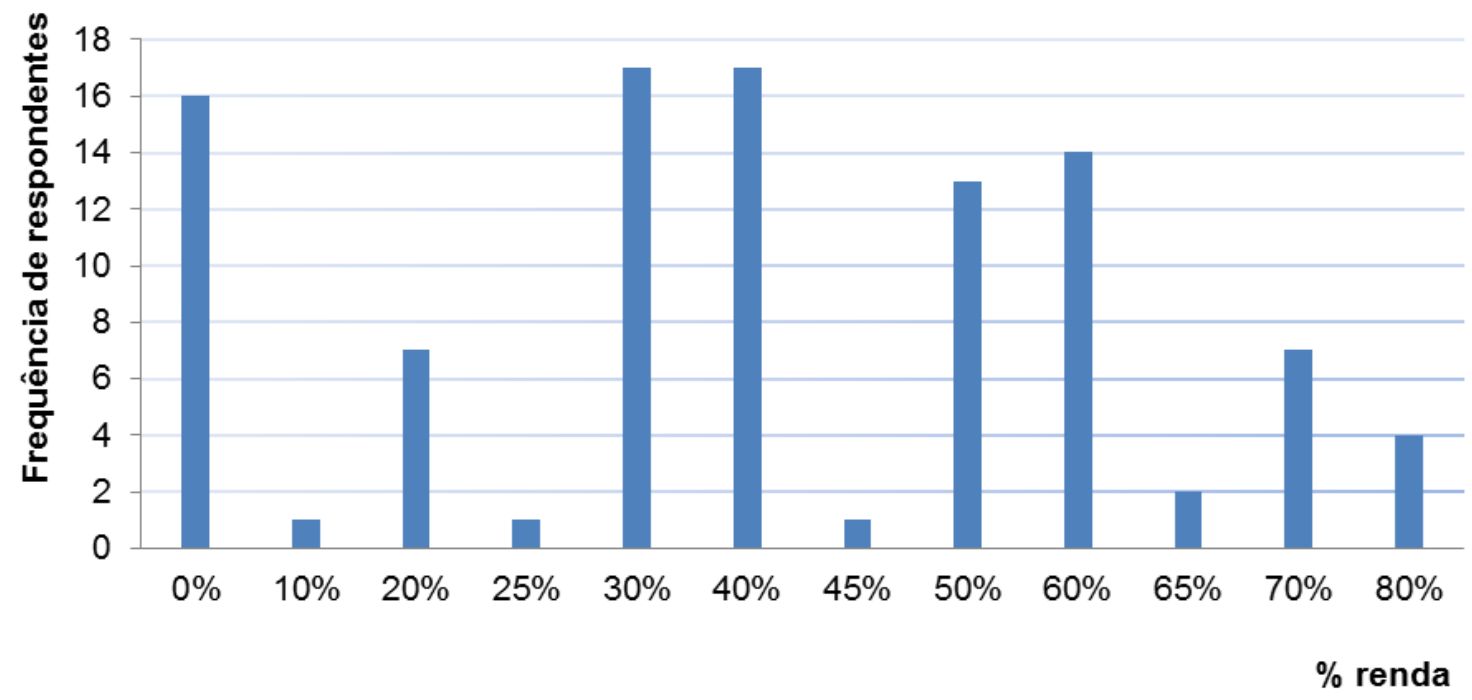

FIGURA 5 - Comprometimento da renda dos produtores rurais de São Pedro das Missões (RS) com o crédito rural FONTE: Dados da pesquisa de campo (2016).

Em relação ao endividamento das famílias, buscou-se saber dos produtores se havia conhecimento destes sobre algum produtor vizinho residente na região que relatam estar em situação de inadimplência. $62 \%$ afirmam ter conhecimento sobre situações de inadimplência de alguns produtores da região. Em alguns casos, o próprio entrevistado afirma ser uma pessoa em situação de endividamento, visto que avalia seus ganhos insuficientes diante dos custos envolvidos na atividade.

Para os produtores do município em questão, a principal causa da inadimplência, o que de fato leva o produtor a deixar de pagar os financiamentos junto às instituições financeiras, relaciona-se à má administração do crédito acessado. Ainda, em alguns casos, o valor acessado junto aos bancos é desviado para outras atividades que não o proposto inicialmente.

Quanto à política de crédito aplicada no Brasil, em relação às melhorias neste contexto, aproximadamente $52 \%$ dos produtores afirmam que poderia melhorar as taxas de juros, consideradas altas pelos entrevistados. Ainda foram citadas como melhorias necessárias: maiores investimentos por parte do governo direcionados, especificamente, ao pequeno produtor, justificando que ainda prevalece a dificuldade encontrada pelo pequeno produtor em ter acesso a este recurso, uma vez que são privilegiados produtores com maiores garantias de pagamento.

Para finalizar, apresentam-se as resposta à última questão do questionário que abrange as ações que o produtor acredita serem necessárias para melhorar a vida no meio rural. De forma geral, as respostas relacionam-se basicamente à infraestrutura dos municípios, principalmente no que diz respeito à situação das estradas, para um melhor escoamento da produção e acesso a municípios vizinhos. De acordo com o relato dos entrevistados, são necessários maiores investimentos, por parte das autoridades responsáveis, na abertura de novas estradas, bem como na manutenção das já existentes.

Os produtores rurais mencionam a necessidade de formação de uma cooperativa liderada por pequenos produtores para conduzir os preços dos produtos, de forma a agregar maior valor à produção $\mathrm{e}$, dessa forma, possibilitar o desenvolvimento do município. A importância de parcerias entre os produtores e município também foram ressaltados pelos entrevistados durante a pesquisa.

Logo, observa-se a disponibilidade dos produtores rurais em instituir parcerias com lideranças locais, organizações públicas e demais agentes, no sentido de promover o desenvolvimento regional. De fato, a geração de sinergias regionais pode ser uma estratégia interessante de superação de vulnerabilidades socioeconômicas.

\section{CONSIDERAÇÕES FINAIS}

A presente pesquisa teve como propósito analisar a disponibilidade e acesso ao crédito rural no Brasil, uma importante ferramenta de política agrícola, no período de 1994 a 2015, bem como contribuir para a discussão envolvendo as implicações que o crescente acesso a este recurso reflete na situação de inadimplência dos produtores rurais do município de São Pedro das Missões, localizado na região Noroeste do Rio Grande do Sul. Para tanto, operou-se por meio de pesquisa bibliográfica, análise documental em banco de dados, principalmente do Banco Central do Brasil, e coleta de dados primários.

Conclui-se que, a partir da implementação do Plano Real, e, consequente estabilidade da economia brasileira, o sistema financeiro sofreu alterações de grande importância para fortalecer o Sistema Nacional 
de Crédito Rural. A partir de então, é possível identificar uma crescente evolução na disponibilidade dos recursos direcionados ao crédito rural e, por conseguinte, um crescente acesso por parte dos produtores em busca do crédito rural.

Nesse sentido, através da pesquisa de caráter descritivo, a coleta de dados primários no município de São Pedro das Missões buscou associar a disponibilidade e acesso dos produtores ao crédito rural ao fenômeno de inadimplência e a percepção destes produtores em relação a este contexto. Desta forma, conclui-se que, dentro da amostra dos produtores rurais entrevistados, não há produtores com dificuldades relacionadas ao endividamento e consequente inadimplência, uma vez que a renda da propriedade se faz suficiente para honrar todos os compromissos assumidos junto a instituições financeiras, bem como gastos familiares. Na maioria dos casos, o comprometimento da renda não ultrapassa os custos associados às atividades da propriedade e os custos familiares.

Através desta análise, pode-se concluir que não há associação da crescente disponibilidade e acesso ao crédito rural com o nível de inadimplência dos produtores rurais do município de São Pedro das Missões. Ainda, pela percepção destes produtores rurais, a principal causa que leva à inadimplência é a má gestão dos recursos acessados, bem como os desvios feitos pelos produtores destes recursos, acarretando em acúmulo de dívidas. Portanto, a principal motivação ao endividamento é exclusivamente auferida ao próprio produtor rural, em não possuir um planejamento e controle da aplicação dos recursos. Isso remete à necessidade de maior assistência técnica ao produtor rural, especialmente àqueles em situação financeira mais vulnerável.

De acordo com a percepção dos produtores rurais em relação à disponibilidade e acesso, estes avaliam como sendo suficientes os valores direcionados ao desenvolvimento das atividades do meio rural. Porém, acreditam que ainda existe, por parte do sistema, uma preferência em beneficiar aqueles produtores que possuem maiores garantias e capacidade de pagamento, excluindo o pequeno produtor ou limitando seu acesso ao crédito rural.

A pesquisa ocorreu em abril de 2016, e, neste período, em meio ao cenário de instabilidade envolvendo a economia do País, a realidade dificultava interpretações válidas para análises prospectivas. Pode-se constatar que o contexto da inadimplência não se configura como uma característica dos entrevistados, porém estes temem as incertezas que envolvem a manutenção da política agrícola no futuro. Os problemas climáticos e oscilações nos preços de insumos que afetam as atividades agrícolas são características que se sobrepõem àqueles referidos pelos produtores no âmbito das políticas governamentais e implicam, de forma decisiva, processos de inadimplência.

Por fim, vale mencionar algumas das principais dificuldades para execução da pesquisa, que incluem a acessibilidade ao público alvo (residentes na zona rural de São Pedro das Missões), o financiamento das atividades de campo (orçadas com recursos próprios) e a abordagem ao público alvo (que, em alguns casos, demonstrou constrangimento ao debater sobre informações pessoais, como renda, endividamento, entre outros). De toda forma, reafirma-se a importância da realização de pesquisas de campo que permitam conhecer com maior propriedade a realidade vivenciada pelos indivíduos que vivem no e do campo.

Neste sentido, sugere-se o desenvolvimento de estudos futuros que possam ampliar a amostragem realizada e explorar a problemática de pesquisa em outras regiões do estado do Rio Grande do Sul. Ainda, vale a realização de estudos que apliquem instrumentos de estatística inferencial para avaliar o comportamento das variáveis endividamento e inadimplência dos produtores rurais em razão da dinâmica de variáveis macroeconômicas.

\section{REFERÊNCIAS}

AGUIAR, L.; FREITAS, M. C. P. Projeto de Estudos sobre as Perspectivas da Indústria Financeira Brasileira e o papel dos Bancos Públicos. Campinas, SP, 2009. Disponível em:< http://www.bndes.gov.br/SiteBNDES/export/sites/default/bndes pt/Galerias/Arquivos/empresa/pesquisa/Subprojetoll.8 PIF.pdf >. Acesso em: 03 jan. 2018.

ALFONSIN, R. Mais juros no crédito rural complica endividamento. [Entrevista disponibilizada em 16 de março de 2015, a Internet]. Disponível em:<http://alfonsin.com.br/mais-juros-no-crdito-rural-complica-endividamento/> Entrevista concedida ao espaço Canal Rural. Acesso em: 17 nov. 2017.

ANDERSON, D. R.; SWEENEY, D. J.; WILLIAMS, T. A. Estatística aplicada a administração e economia. São Paulo: Editora Cengage Learning, 2007.

ANDRADE, M. G. Introdução a Metodologia do Trabalho Cientifico. São Paulo: Atlas, 2010.

BANCO DO BRASIL. Recursos do Banco do Brasil para o Agronegócio. Brasília, 2015. Disponível em: < http://www.bb.com.br/portalbb/page118,3360,3367,1,0,1,0.bb?codigoNoticia=25624 >. Acesso em: 03 jun. 2016.

BANCO CENTRAL DO BRASIL. Manual de Crédito Rural - MCR. Brasília, 2015. Disponível em: <http://www3.bcb.gov.br/mcr >. Acesso em: 10 nov. 2017.

BANCO CENTRAL DO BRASIL. Matriz de Dados do Crédito Rural. Brasília, 2015. Disponível em: 
<http://www.bcb.gov.br/en/\#!///MICRRURAL/>. Acesso em: 10 nov. 2017.

BANCO CENTRAL DO BRASIL. Boletim Anual, Boletim Regional. A economia brasileira. Disponível em:<http://www.bcb.gov.br/pec/boletim/banual2005/rel2005cap1p.pdf>. Acesso em:11 jan. 2018.

BRAUN, M. B. S.; SHIKIDA, P.F.A. Uma análise da Balança Comercial Agrícola Brasileira à guisa de sua Evolução histórica recente. 2004. Disponível em: < http://www.sober.org.br/palestra/12/030178.pdf > Acesso em: 03 jan. 2018.

CAIXA ECONÔMICA FEDERAL. Crédito Rural; Crédito de Comercialização. Disponível em: $<$ http://www.caixa.gov.br/empresa/credito-financiamento/credito-rural/comercializacaocooperativas/Paginas/default.aspx >. Acesso em: 10 dez. 2017.

MACEDO, M. F. S. Técnicas de irrigação, o desenvolvimento da agricultura e do agronegócio: uma análise à luz da proteção humana e da cidadania frente à crise hídrica nacional. Campo Jurídico, v. 3, n. 2, out., 2015.

COELHO, C. N. "70 anos de Política Agrícola no Brasil (1931 - 2001)". Revista de Política Agrícola. Brasília, 2001, Ed. especial. Disponível em: <http://www.agricultura.gov.br/arq editor/Revista\%20de\%20Politica\%20Agricola\%20\%20Ano\%20X\%20-\%20No\%2003\%20-\%20Jul\%20-\%20Ago\%20-\%20Set\%20-\%202001.pdf >. Acesso em: 04 dez. 2018.

EMBRAPA. Empresa Brasileira de Pesquisa Agropecuária. A EMBRAPA. Brasília, 2015. Disponível em: <https://www.embrapa.br/>. Acesso em: 30 nov. 2017.

FIALHO, A. V.; REDIN, E. Política Agrícola Brasileira: uma análise histórica da inserção da Agricultura Familiar. Santa Maria, 2009. Disponível em: < http://www.sober.org.br/palestra/15/922.pdf>. Acesso em: 04 dez. 2017.

GIL, A. C. Como Elaborar Projetos de Pesquisa. São Paulo: Atlas, 2017.

INSTITUTO BRASILEIRO DE GEOGRAFIA E ESTATISTICA. Cidades: Informações sobre municípios brasileiros. Disponível em:<http://www.cidades.ibge.gov.br/xtras/home.php >. Acesso em: 24 nov. 2017.

IPEA. INSTITUTO DE PESQUISA ECONÔMICA APLICADA. Políticas sociais: Acompanhamento e Análise. Brasília, 2011. Disponível em: <http://www.ipea.gov.br/agencia/images/stories/PDFs/politicas sociais/bps 19 completo.pdf $>$. Acesso em: 03 jan. 2018.

MASSUQUETTI, A. A mudança no padrão de financiamento da agricultura brasileira no período de 1965-97. 1998. Tese (Programa de Pós-Graduação em Economia Rural) - Universidade Federal do Rio Grande do Sul, Porto Alegre, RS, 1998.

MICHEL, M. H. Metodologia e Pesquisa Cientifica em Ciências Sociais. 2. ed. São Paulo: Atlas, 2009.

MINISTÉRIO DA AGRICULTURA PECUÁRIA E ABASTECIMENTO. Estatísticas e Dados Básicos de Economia Agrícola. 2016. Disponível em: < http://www.agricultura.gov.br/arq editor/Pasta\%20de\%20Abril\%20\%202016.pdf > Acesso em: 11 dez. 2017.

MINISTÉRIO DA AGRICULTURA PECUÁRIA E ABASTECIMENTO. Plano Agrícola e Pecuário 2015/2016. Brasília, 2016. Disponível em: <http://www.agricultura.gov.br/pap >. Acesso em: 10 nov. 2017.

MINISTÉRIO DA AGRICULTURA PECUÁRIA E ABASTECIMENTO. Agropecuária se destaca e gera 9,8 mil empregos em 2015. Disponível em: <http://www.agricultura.gov.br/comunicacao/noticias/2016/01/agropecuaria-sedestaca-e-gera-9-mil-empregos-em-2015 >. Acesso em: 10 nov. 2017.

MINISTÉRIO DA AGRICULTURA PECUÁRIA E ABASTECIMENTO. Agronegócio brasileiro: Perspectivas 2016. Brasília, 2015. Disponível em: <http://www.agricultura.gov.br//arq editor/PRESIDENTE V Final1.pdf >. Acesso em: 10 nov. 2015.

MINISTÉRIO DA AGRICULTURA PECUÁRIA E ABASTECIMENTO. Revista de Política Agrícola. Brasília, 2005, 21 ed. Disponível em: <http://www.agricultura.gov.br/arq editor/Revista\%203\%2005.pdf > Acesso em: 24 nov. 2017.

NAKAGAWA, F. Revista Exame.Com. Brasil cai para a posição de 9a economia do mundo. 2015. Disponível em: < http://exame.abril.com.br/economia/noticias/pib-em-dolar-cai-25-e-brasil-cai-para-a-posicao-de-9a-economia-do-mundo >. Acesso em: 10 nov. 2017.

ONUBR, NAÇÕES UNIDAS NO BRASIL. A ONU e a população mundial. Disponível em: $<$ https://nacoesunidas.org/acao/populacao-mundial//>. Acesso em: 24 nov. 2017.

SCHULTZ, G. WAQUIL, P.D. Políticas Públicas e Privadas e Competitividade das Cadeias Produtivas Agroindustriais. Porto Alegre: UFRGS, 2011.

SNA, Sociedade nacional da Agricultura. Cresce inadimplência no crédito rural. Rio de janeiro, 2016. Disponível em: $<$ http://sna.agr.br/cresce-inadimplencia-no-credito-rural/> Acesso em: 29 ago. 2017.

STEVENSON, W. J. Estatística aplicada a administração. São Paulo: Harbra, 1986.

TOSCHI, A. B. As fontes de Recursos do Crédito Rural no Brasil de 1994 a 2004. 2006. Tese (Programa de PósGraduação em Economia) - Universidade Federal do Rio Grande do Sul, Porto Alegre, RS, 2006. 
